\title{
Genetic and environmental factors in polymyalgia rheumatica
}

Polymyalgia rheumatica (PMR) is a disease that rheumatologists feel confident in recognising in their daily practice. In the classic form, its diagnosis is straightforward and standard corticosteroidal treatment usually yields excellent results, at least in the first months. In contrast with the feeling that PMR is a disease that can be readily treated, the aetiology and pathogenesis are still obscure. Unlike several other forms of rheumatic disease, we do not know what the target of inflammation is in PMR. The synovial membrane is the most probable candidate as synovitis has been demonstrated by sonographic ${ }^{1}$ and immunohistochemical ${ }^{2}$ methods. In addition, the frequent occurrence of peripheral arthritis in patients with PMR further supports this possibility. ${ }^{3}$ Synovitis is mild and patchy in extent, which does not explain the amount of inflammation disclosed by symptoms and laboratory tests. The skeletal muscle was considered the main site of inflammation by Barber ${ }^{4}$ who coined the name 'polymyalgia rheumatica'. Although this theory has been discarded for a long time, recent descriptions of the association between PMR and mitochondrial myopathy ${ }^{5}$ and of corticosteroid responsive electromyographic abnormalities ${ }^{6}$ in patients with PMR have reawakened interest in the role of skeletal muscles. Vasculitis is another attractive possibility because it could comprise PMR and giant cell arteritis (GCA) under a common pathogenesis. The evidence for active vasculitis in biopsy specimens from patients with PMR, however, is scanty. There are also new data that point to bursae as the principal site of inflammation. ${ }^{7}$ The large surface of synovial tissue in bursae around glenohumeral joints could explain the amount of inflammation seen in PMR.

The main areas of research in PMR aetiopathogenesis are immunology, genetics, and the environment.

\section{Immunology}

The concept that PMR cannot be an autoimmune disease because of the lack of autoantibodies has been challenged by the finding of anti-lamin B2 antibodies specific for the $\mathrm{C}$ terminus in PMR patients. ${ }^{8}$ Other findings that suggest involvement of the immune system are the decrease of circulating CD8+ lymphocytes, ${ }^{9}$ which return to normal values with remission, the increased concentration of soluble CD $8,{ }^{10}$ soluble interleukin 2 (IL2) receptors ${ }^{11}$ and intercellular adhesion molecule $1,{ }^{12}$ and the pattern of cells infiltrating the synovial membrane. These are mainly CD4+ lymphocytes and macrophages with intense expression of HLAII class antigens. ${ }^{2}$ This pattern, which is very close to that seen in GCA, ${ }^{13}$ is highly suggestive of efficient antigen presentation and of consequent antigen driven immune inflammation.

\section{Genetics}

The role of genetic predisposition in PMR has been suspected because of the geographical distribution of the disease. The incidence is higher in northern Europe than in the south. The same trend can be observed in the US, with a high incidence in Minnesota, ${ }^{14}$ a state with a large population of Scandinavian stock, and low incidence in the south. PMR is virtually absent in Africans and African-Americans. This geographical distribution is similar to that seen for rheumatoid arthritis (RA) and multiple sclerosis, which share with PMR an association with HLA DR4. Weyand et al showed however that PMR and GCA, which are genetically related, differ from RA. ${ }^{15}$ PMR and GCA share the associated sequence polymorphism (DYF) encoded by the second hypervariable region of the HLA-DRB1 gene. In contrast, RA is linked to a sequence motif in the third hypervariable region of DRB1 alleles. ${ }^{15}$ Recent findings from the UK, however, have shown similar HLA profiles in patients with PMR and in those with RA. ${ }^{16}$ Further support to the genetic component of PMR has been given by Johansen et al who have shown that CD8+ cells depletion is present also in relatives of patients with GCA or PMR. ${ }^{17}$

\section{Environment}

The geographical trend described above could also suggest environmental factors. Infectious agents have been extensively studied because the acute onset of PMR and its systemic symptoms resemble those of an infectious disease. In addition, an increased frequency of trivial infections before the onset of GCA has been shown in a series of patients. ${ }^{18}$ Serological reports have given poor results, ${ }^{19}$ however, except for an increased prevalence of antibodies to respiratory syncytial virus and to adenovirus observed in Italy. ${ }^{20}$ Although these findings suggest that trivial infections may trigger PMR in elderly subjects, molecular biology techniques should be applied to provide direct evidence of infection in the affected tissues.

Epidemiological data regarding PMR and GCA also suggest an infection. The cyclic pattern observed in the incidence of GCA in Rochester is in agreement with the theory of population immunity after infection. ${ }^{21}$ A similar study performed in Denmark found correlations between the incidence peaks of PMR and epidemics of parvovirus B19, Mycoplasma pneumoniae, and Chlamydia pneumoniae infections. ${ }^{22}$ Parvovirus B19 is an interesting candidate for the aetiological agent of PMR/GCA because it has been involved in the aetiopathogenesis of other vasculitides such as Kawasaki syndrome, ${ }^{23}$ Wegener's granulomatosis and polyarteritis nodosa. ${ }^{24}$ In addition, $\mathrm{P}$ antigen, the receptor of parvovirus $\mathrm{B} 19$ on erythrocytes, is present also on endothelial cells. ${ }^{25}$

Environmental factors could help explain why PMR is a disease of the elderly and why the associated GCA is preferentially located in the temporal artery. O'Brien and Regan have proposed that long term exposure to sunlight, including infrared and ultraviolet radiation, can change the internal elastic lamina of the arteries making it antigenic. ${ }^{26}$ These authors found lesions similar to those observed in GCA in the temporal and posterior ciliary arteries of aged subjects. ${ }^{27}$ Alternatively, normal aging of the arteries may predispose to an autoimmune reaction against arterial constituents. In addition, aging of the immune system, including a comparatively deficient cortisol response to stress, may be the cause of the persistent inflammation seen in PMR. ${ }^{28}$ Although the elastic tissue could be an ideal antigen for the autoimmune response in PMR and GCA, there is no experimental evidence for this hypothesis.

On the other hand, the role of sun exposure is supported by the finding of a seasonal trend in the onset of $\mathrm{PMR}^{29}$ and $\mathrm{GCA}^{30}$ and of its association with the risk for PMR. ${ }^{31}$ However, a seasonal trend was not observed in Rochester. ${ }^{14}$ The major objection to this hypothesis is that epidemiological studies have shown a higher incidence of PMR in northern countries where sun radiation is less intense. A possibility is that sun exposure acts in combination with genetic predisposition. Skin sensitivity may also modulate the effect of sun radiation on dermal arteries. In fact, people of Nordic origin usually show a light complexion, which is associated with a very low defence from sun radiations. This hypothesis would also explain the predilection of GCA for the temporal artery because this superficial artery of the scalp is directly exposed to light. 


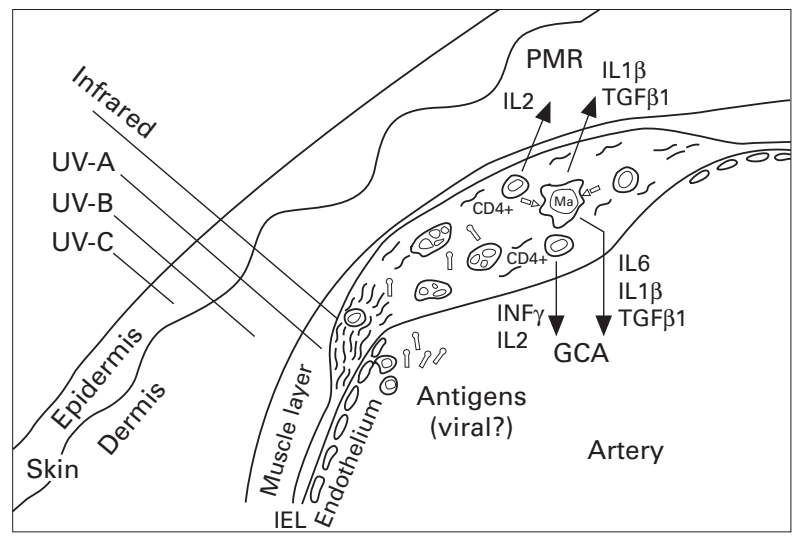

Figure 1 Sun radiation of both the infrared and ultraviolet $A$ types damages the internal elastic lamina (IEL) of superficial arteries facilitating the localisation of an unknown aetiological agent (viral proteins or degenerated vascular components?). This antigen is presented by macrophages (Ma) and is recognised by CD4+ lymphocytes in the context of class II MHC molecules. Macrophages and lymphocytes are stimulated to produce increased amounts of cytokines, which can lead to PMR or to GCA, depending on their pattern. This mechanism is facilitated by predisposing factors, such as old age, female sex, and specific HLA-DRB1 alleles.

Based on the immunological, genetic, and environmental data mentioned above, the following mechanism could be hypothesised for the aetiopathogenesis of PMR (fig 1). In a predisposed subject because of old age, female sex, and specific HLA-DRB1 alleles the superficial arteries may be damaged by atherosclerosis or sun induced elastic fibre degeneration. The damaged elastic layer, and possibly the synovial membrane, may be reached by viral antigens. Interestingly, several viruses, including adenovirus, may persist for a long time in a latent form and can be reactivated by physical stimuli such as heat. ${ }^{32}$ Recognition of the still unknown antigen by TH1 CD4+ lymphocytes after class II MHC mediated presentation by macrophages leads to cytokines production. Activated CD4+ lymphocytes and macrophages produce an increased concentration of IL2, interferon $\gamma$, and of IL1 $\beta$, IL6, and transforming growth factor $\beta 1$, respectively. Interestingly, interferon $\gamma$ has an antiviral activity and its production is increased after viral infection. An incomplete pattern of cytokines (IL1 $\beta$, transforming growth factor $\beta 1$, IL2) is associated with a prevalently extravascular disease typical of PMR whereas the addition of IL6 and interferon $\gamma$ could represent an amplification loop leading to arteritis. ${ }^{13}$

The scheme reported in figure 1 is an attempt at combining the genetic and environmental hypotheses. Both of them seem to be at work in PMR as confirmed by case reports describing the disease in close relatives ${ }^{33}$ or in non-consanguineous subjects living in the same environment. $^{34}$ However, the relative weight of genetic and environmental factors may differ in different geographical areas. It is obvious that many pieces of the puzzle are still missing. The temporal artery seems to be the site of an active immunological reaction in both GCA and PMR but the mechanisms leading to the articular or periarticular involvement of PMR are still unclear. Further epidemiological studies are needed on the correlation between incidence of PMR and epidemics of infectious diseases, collection of microbiological and HLA data of family cases, and the demonstration of bacterial or viral antigens in the affected tissues.

MARCO A CIMMINO Cattedra di Reumatologia, Dipartimento di Medicina Interna, Università di Genova, Genova, Italy

Correspondence to:

Dr M A Cimmino, Cattedra di Reumatologia, DIMI, Viale Benedetto XV 6, 16132 Genova, Italy.
1 Koski JM. Ultrasonographic evidence of synovitis in axial joints in patients with polymyalgia rheumatica. Br J Rheumatol 1992;31:201-3.

2 Meliconi R, Pulsatelli L, Uguccioni M, Salvarani C, Macchioni P, Melchiorri C, et al. Leukocyte infiltration in synovial tissue from the shoulder of patients with polymyalgia rheumatica. Arthritis Rheum 1996; 39:1199-207.

3 Healey LA. Long-term follow-up of polymyalgia rheumatica: evidence for synovitis. Semin Arthritis Rheum 1984;13:322-8.

4 Barber HS. Myalgic syndrome with constitutional effects: polymyalgia rheumatica. Ann Rheum Dis 1957;16:230-7.

5 Harle JR, Pelissier JF, Desnuelle C, Disdier P, Figarella-Branger D, Weiller PJ. Polymyalgia rheumatica and mitochondrial myopathy: clinicopathologic and biochemical studies in five cases. Am J Med 1992;92:167-2.

6 Bromberg MB, Donofrio PD, Segal BM. Steroid-responsive electromyographic abnormalities in polymyalgia rheumatica. Muscle Nerve 1990; 13:138-41.

7 Cantini F, Niccoli L, Salvarani C, Macchioni P, Olivieri I, Padula A, et al. Shoulder and hip magnetic resonance imaging in active polymyalgia rheumatica. [Abstract]. Arthritis Rheum 1996;39 (suppl):S201.

8 Brito J, Biamonti G, Caporali R, Montecucco C. Autoantibodies to human nuclear lamin B2 protein. Epitope specificity in different autoimmune diseases. J Immunol 1994;153:2268-77.

9 Boiardi L, Salvarani C, Macchioni P, Casadei Maldini M, Mancini R, Beltrandi $\mathrm{E}$, et al. CD8 lymphocyte subsets in active polymyalgia rheumatica: comparison with elderly-onset and adult rheumatoid arthritis and influence on prednisone therapy. Br J Rheumatol 1996;35:642-8.

10 Salvarani C, Boiardi L, Macchioni P, Casadei Maldini M, Mancini R, Beltrandi E, et al. Serum soluble CD4 and CD8 levels in polymyalgia rheumatica. J Rheumatol 1994;21:1865-69.

11 Salvarani C, Macchioni P, Boiardi L, Rossi F, Casadei Maldini M, et al. Soluble interleukin 2 receptors in polymyalgia rheumatica/giant cell arteritis. Clinical and laboratory correlations. J Rheumatol 1992;19:1100-6.

12 Macchioni P, Boiardi L, Meliconi R, Salvarani C, Uguccioni MG, Rossi F, et al. Elevated soluble intercellular adhesion molecule 1 in the serum of patients with polymyalgia rheumatica: influence of steroid treatment. J Rheumatol 1994;21:1860-64.

13 Weyand C, Hicok KC, Hunder GG, Goronzy JJ. Tissue cytokine patterns in patients with polymyalgia rheumatica and giant cell arteritis. Ann Intern patients with polymyal

14 Salvarani C, Gabriel SE, Metz EW, O'Fallon WM, Hunder GG. Epidemiology of polymyalgia rheumatica in Olmsted county, Minnesota, 1970-1991. Arthritis Rheum 1995;38:369-73.

15 Weyand C, Hunder NNH, Hicok K, Hunder GG, Goronzy JJ. HLA-DRB1 alleles in polymyalgia rheumatica, giant cell arteritis, and rheumatoid arthritis. Arthritis Rheum 1994;37:514-20.

16 Haworth S, Ridgeway J, Stewart I, Dyer PA, Pepper L, Ollier W. Polymyalgia rheumatica is associated with both HLA-DRB $1{ }^{\star} 0401$ and $\mathrm{DRB} 1{ }^{\star} 0404$. Br J Rheumatol 1996;35:632-5.

17 Johansen M, Elling P, Elling H, Olsson A. A genetic approach to the aetiology of giant cell arteritis: depletion of the CD8+ T-lymphocyte subset in relatives of patients with polymyalgia rheumatica and arteritis temporalis. Clin Exp Rheumatol 1995;13:745-8.

18 Russo MG, Waxman J, Abdoh AA, Serebro LH. Correlation between infection and the onset of the giant cell (temporal) arteritis syndrome. Arthritis Rheum 1995;38:374-80.

19 Bacon PA, Doherty SM, Zuckerman AJ. Hepatitis-B antibody in polymyalgia rheumatica. Lancet 1975;ii:476-8.

20 Cimmino MA, Grazi G, Balistreri M, Accardo S. Increased prevalence of antibodies to adenovirus and respiratory syncytial virus in polymyalgia rheumatica. Clin Exp Rheumatol 1993;11:309-13.

21 Salvarani C, Gabriel SE, O'Fallon WM, Hunder GG. The incidence of giant cell arteitis in Olmsted county, Minnesota: apparent fluctuations in a cyclic pattern. Ann Intern Med 1995;123:192-4.

22 Elling P, Olsson AT, Elling H. Synchronous variations of the incidence of temporal arteritis and polymyalgia rheumatica in different regions of Denmark; association with epidemics of mycoplasma pneumoniae infection. J Rheumatol 1996;23:112-9.

23 Nigro G, Zerbini M, Krzysztofiak A, Gentilomi G, Porcaro MA, Mango T, et al. Active or recent parvovirus B19 infection in children with Kawasak disease. Lancet 1994;343:1260-1.

24 Finkel TH, Torok TJ, Ferguson PJ, Durigon EL, Zaki SR, Leung DYM, et al. Chronic parvovirus B19 infection and systemic necrotizing vasculitis: opportunistic infection or aetiological agent? Lancet 1994;343:1255-8.

25 Brown KE, Anderson SM, Young NS. Erythrocyte P antigen: cellular receptor for B19 parvovirus. Science 1993;262:114-7.

26 O'Brien JP, Regan W. Are we losing focus on the internal elastic lamina in giant cell arteritis? Arthritis Rheum 1992;35:794-8.

27 O'Brien JP. A controlled hematoxylin-eosin for actinic elastosis-lysis. Am J Dermatopathol 1994;16:31-5.

28 Stevens RJ, Hughes RA. The aetiopathogenesis of giant cell arteritis. Br J Rheumatol 1995;34:960-5.

29 Cimmino MA, Caporali R, Montecucco CM, Rovida S, Baratelli E, Broggini M. A seasonal pattern in the onset of polymyalgia rheumatica. Ann Rheum Dis 1990;49:521-3.

30 Sonnenblick M, Nesher G, Friedlander Y, Rubinow A. Giant cell arteritis in Jerulasem: a twelve year epidemiological study. $\mathrm{Br} \mathrm{J}$ Rheumatol 1994;33:938-41

31 Cimmino MA, Accardo S, Montecucco C, Caporali R, Cappelli A, Broggini $M$. Sun exposure and the polymyalgia rheumatica-giant cell arteritis complex. Clin Exp Rheumatol 1994;12:229-30.

32 Piperakis SM, McLennan AG. Hyperthermia enhances the reactivation of irradiated adenovirus in HeLa cells. Br J Cancer 1984;49:199-205.

33 Wernick R, Davey $M$, Bonafede P. Familial giant cell arteritis: report of an HLA-typed sibling pair and a review of the literature. Clin Exp Rheumatol 1994;12:63-6.

34 Faerk KK. Simultaneous occurrence of polymyalgia rheumatica in a married couple. J Intern Med 1992;231:621-2. 